\title{
Research on the Relationship between Electricity Consumption and Economic Growth
}

\author{
Yantao Wang ${ }^{a}$, Xiaomei Liu ${ }^{b^{*}}$ and Suiliang Liu $^{c}$ \\ School of Economics and Management, Northeast Dianli University, Jilin 132012, China \\ awangyantao@gmail.com, b934662645@qq.com, '1156455527@qq.com \\ *The corresponding author
}

Keywords: Electricity consumption; Economic growth; Electricity elasticity coefficient; Electricity demand

\begin{abstract}
Based on the research of many scholars on the relationship between electricity and economy, from the industrial structure, the electricity elasticity coefficient and electricity consumption of three different perspectives on this to make a review, from two aspects of the national and regional expansion respectively, and the research on the relationship between electricity and economy make the forecast, in order to study the relationship between electricity consumption and economic growth to make a reference.
\end{abstract}

\section{Introduction}

Electric energy is the driving force of economic development, the electricity industry is the basic industry of national economic development, the production and adequate supply of electricity for economic development, and social progress and people's life provide an indispensable condition. Economic development is inseparable from the support of electrical energy, and the development of electricity cannot be separated from the needs of the development of the macro-economy, adequate electricity supply and consumption can guarantee a high level of national economy growth. In real life, due to power shortages often occur "Power rationing" phenomenon; it severely restricted the development of Chinese economy. The current problem of electricity and economy is that it is not a good combination of the two. In improving the efficiency of electricity utilization, China's electricity consumption of promoting economic development remains to be improved.

\section{Research Statuses}

Electricity Demand of Different Industrial Structure. Different stages of economic development have different industrial structure. At present, China's industrial structure in the secondary industry especially the growth of industry in the development of the national economy occupies the main position, and the secondary industry is the large electric energy user. Lin Weibin [1] does a quantitative analysis on the impact of economic growth and structural change to the power consumption. The results shows, electricity consumption growth rate of production sectors increased by $0.58 \%$ while each percentage point gained by the growth rate of GDP. And it improved by $1.89 \%$ while the proportion of heavy industry output value increased by $1 \%$. And changes in the industrial structure are an important factor in economic growth and electricity consumption that are not synchronized. Wenchao Wang [2] uses a logarithmic mean Divisia index I decomposition method to analyze the potential factors influencing the growth of electricity consumption in China's industrial sector from 1998 to 2007.The results show that the main contributors to incremental electricity consumption among industrial subsectors were manufacturing of raw chemical material and products, manufacturing of non-metal mineral products, smelting and pressing of ferrous and non-ferrous metals, and production and supply of electric power and heat power. Paul A. Steenhof [3] proposes analysis of the effect of changes in the industrial sector on electricity demand, an important economic sector contributing to these above patterns as it consumes nearly $70 \%$ of the electricity generated in China. 
Using decomposition analysis, it is concluded that increased industrial activity and fuel changes helped increase industrial sector electricity demand from 1998 to 2002. B.W. Ang[4] discusses the decomposition technique for identifying the relative contributions of output growth, structural change and energy intensity to changes in industrial energy consumption through analyzing the data on electricity consumption in UK industry. From the above study, we learn that economic growth is closely related to the second industrial electricity consumption. And attaching great importance to the second industry demand for electricity and tariff policy playes a positive role in promoting the development of the national economy.

Electricity Elasticity Coefficient. Electricity elasticity coefficient is usually divided into elasticity coefficient of electricity production and elasticity coefficient of electricity consumption. Economists generally apply electricity consumption elasticity coefficient to do research. Electricity consumption elasticity coefficient is the ratio of a period of time on the growth rate of electricity consumption and GDP growth rate. It is a general indicator of describing the general trend of development in macroeconomics, which is used to evaluate the overall relationship between electricity and economy.

Electricity elasticity coefficient is usually used to study the matching degree of a country's energy development and economic development internationally. When a country is in the period of rapid development of industrialization, general electricity consumption growth rate accelerates; electricity consumption is growing faster than the pace of development of the national economy with electrical elasticity coefficient is generally greater than 1 . When completed the industrialization process of the country, electricity elasticity coefficient is generally less than 1. Statistics show that the U.S. electricity elasticity coefficient was 2.0 in 1931 -1948. Rose to 2.5 in 1951-1960, decreased to 1.6 in 1961-1980, and was only 0.5 in 1980-1993. As for China, electricity elasticity coefficient is on a downward trend, but it recently is not stable. Since 2008, China`s electricity elasticity coefficient is of rapid rise and rapid decline., it fell to 0.51 in 2014; in 2015 of the first quarter, it fell to 0.12 , reaching even far below the level of developed countries. Therefore, the study of electricity elasticity coefficient has been the hot spot of concern. Jiang Jinhe [5] analyzes factors affecting the country's electricity consumption for the period of 1990-2000 by using electricity elasticity coefficient, including industrial structure, product structure, technological progress and macroeconomic policy analysis to conclude relation mutations of electricity and economic development in the short term, which is conducive to judge and analyze the future development trend of the electricity industry. Shu Fan ${ }^{[6]}$ undertakes a review of the scholarly literature regarding electricity price elasticity for different regions and systems. Then he performs an empirical evaluation of the historic South Australian price elasticity, focussing on the relationship between price and demand quantiles at each half-hour of the day.

Based on the electricity elasticity coefficient, combined with different industries in the development and change of electricity consumption and electricity production from 1993 to 2002,Si Zengchuo [7] analyzes the general rules of the electricity consumption level and economic development process, the electricity consumption elasticity coefficient and its historical evolution and relativity between industrial processes and the evolution processes of the electricity consumption elasticity coefficient. He concludes that electricity consumption elasticity coefficient directly measures the relative velocity of growth in electricity consumption and economic growth and proposes that the innovation of technology should be strengthened for current coordinated development of economy and electricity. Through application of the grey control system modeling and empirical analysis method, Qiu Weijie [8] analyzes effects on electricity consumption elasticity coefficient by GDP, investment in fixed assets, the amount of electricity consumption, the level of resident's consumption index and population. And he further optimizes model to determine the extent of change in China's electricity consumption elasticity coefficient, thus to provide an important reference for the power industry and the healthy development of the national economy. Studies of the above scholars on electricity elasticity coefficient are inseparable from the electricity industry-related datas and indicators. We believe that there is a simultaneous increase between the development of the electricity industry and the national economy, which can ensure electricity demands of national economic development. 
Electricity Consumption and Economic Growth. Causality analyses of electricity consumption and economic growth for revealing the intrinsic link between the two have a major impact on the national energy conservation, electricity planning and economic development policy. Different scholars have made a lot of researches on this.

Sajal Ghosh[9] tries to examine the Granger causality between electricity consumption per capita and Gross Domestic Product (GDP) per capita for India using annual data covering the period 1950-1951 to 1996-1997. It is concluded that the absence of long-run equilibrium relationship among the variables, but there exists unidirectional Granger causality running from economic growth to electricity consumption without any feedback effect. Based on three elements production function model, Lin Boqiang [10] applies cointegration analysis and error correction model technique to study the relationship between the Chinese electricity consumption and economic growth. It is concluded that there is a long-term stable equilibrium relationship between human capital, GDP capital and electricity consumption. This evidence strongly supports that China's electricity consumption and economic growth are endogenous, and these two variables are interrelated hypotheses. Based on the panel data of China 30 provinces from 1990 to 2011, using cointegration test and vector error correction model to form multivariate analysis framework, Muhammad Shahbaz [11] studies the relationship between electricity consumption and economic growth in Pakistan by controlling and investigating the effects of two major production factors - capital and labor, indicating that electricity consumption has a positive effect on economic growth. Li Ke [12] analyzes that economic growth, industrial structure, all elements of the electricity efficiency and electricity price have different effects on electricity consumption using a threshold regression model in different phases of economic growth, and based on this he reveals non- asymmetry effects between Chinese electricity consumption growth and economic growth in 1908-- 2008. The results show that, quickly development of heavy industry significantly contributes to the increase of electricity consumption in economic expansion, electricity use efficiency effectively inhibits the excessive growth of electricity consumption in economic slowdown. Paresh Kumar Narayan[13] examines the causality between electricity consumption, exports and gross domestic product (GDP) for a panel of Middle Eastern countries. It is concluded that for the panel as a whole there are statistically significant feedback effects between these variables. Electricity consumption increases $1 \%$ while GDP increases by $0.04 \%$ and a $1 \%$ increase in GDP generates a $0.95 \%$ increase in electricity consumption. Investing in electricity infrastructure and stepping up electricity conservation policies to avoid a reduction in electricity consumption adversely affecting economic growth.

Based on the statistical data from 1952 to 2002, James E. Payne[14] discusses the various hypotheses associated with the causality between electricity consumption and economic growth by a survey of the empirical literature. The results show that $31.15 \%$ supported the neutrality hypothesis; $27.87 \%$ the conservation hypothesis; $22.95 \%$ the growth hypothesis; and $18.03 \%$ the feedback hypothesis. According to data from 1980 to 2009, Niu Dongxiao [15] uses model margin Cointegration of autoregressive distributed lag (ARDL) and Granger causality test based on error correction model to test causality of China's electricity consumption and economic growth. The study shows that there exists a significant long-term one-way causality between electricity consumption and economic development and apparent short-term two-way causality between fluctuations of the two. And it proposes to maintain the normal growth of electricity supply to China's economic growth has a stimulating effect. Based on total electricity consumption, toward interdependence investigation causality between Poland electricity consumption and GDP, Henryk Gurgul [16] carries out a survey that taking a three-dimensional framework and employment options as an additional variable. Study on relationship between electricity consumption of whole society and GDP in Poland shows that there exists a feedback between the total electricity consumption and gross domestic product as well as the total electricity consumption and employment. Alice Shiu[17] tests causality between electricity consumption and the actual GDP from 1971 to 2000 in China by applying error correction model. The 
results show that there exists cointegration of China's real GDP and electricity consumption and unidirectional Granger causality from electricity consumption to real GDP, not vice versa.

Reviews of the Relationship between Electricity and Economic in Different Regional. As can be seen from the foregoing literature review, most scholars macrocosmically analyze the relationship between electricity and economy in nationwide. But regional electricity and economic development is uneven, as well as electricity production and consumption, while it is difficult to take scientific measures to coordinate with different regional electricity and economic development. According to the factors of industrial structure changes and economic development in Henan Province, Dong Zhi [18] analyzes historical change of electricity consumption elasticity coefficient and forecasts the change trends of electricity consumption elasticity coefficient in the next five years, which provides important reference significance for forecasting future demand and electricity consumption in Henan Province.

The electricity supply capacity of Jilin province has a large surplus, the power generating unit is too large, and the power construction exceeds economic needs, resulting in serious waste of resources and great pressure of resources environment. Therefore, it has important theoretical and practical significance to study the relationship between regional electricity and economy in Jilin province. Currently, only a small part of the scholars make a thorough research on the relationship between electricity and economy of Jilin Province. Based on datas of Jilin Province from 1978 to 2010, Zhou Jinghong [19] uses co-integration theory to empirically analyze the relationship between electricity consumption and economic growth and establishes co-integration and error correction model between electricity consumption and GDP in Jilin province. The analysis shows that there is a one-way causality between electricity consumption and economic growth in Jilin Province. Through the description of electricity elasticity coefficient and unit consumption method of output value in Jilin Province over the years.

\section{The Prospect of the Research on the Relationship between Electricity and Economy}

Future research should aim at the current situation between the lack of new economic growth energy and the reduction of old power and make more analysis on the better fit between electricity and energy. China's sustained 10 years of heavy and chemical industrialization stage has been near the end with a clearer trend on economy dominated from industry to service sector. In the future electric energy demand outlook, we should aim to enhance the tertiary industry electricity demand. Since there is no market in electricity industry and resource efficiency is not very high easily leading to unflexible pricing mechanism, the study on relations of power and economic should also focus on the reform of electricity. In the previous studies, it should be combined with electricity energy structure, the electricity demand of industrial structure and economic development trends in Jilin Province to make a detailed study and analysis.

\section{Acknowledgements}

The work of this paper is supported by the research project of Humanities and Social Sciences in the Education Department of Jilin Province (Project No.182 [2015]) and Social Science Foundation of Jilin Province, China (2015A2).

\section{References}

[1] Lin Weibin. Economic Growth, Structure Change and Electric Power Consumption-Why Is Economic Growth and Electric Power Consumption Are not Synchronized [J]. Economic Theory and Business Management,2010, (2)

[2] Wenchao Wang. Changes in Industrial Electricity Consumption in China from 1998 to 2007[J]. Energy Policy,2010,38(7):3684-3690 
[3] Paul A. Steenhof. Decomposition of Electricity Demand in China's Industrial Sector [J]. Energy Economics,2006,28(3): 370-384

[4] B.W. Ang. Structural Change, Sector Disaggregation and Electricity Consumption in UK Industry [J]. Energy \& Environment, 1994,5:11-16

[5] Jiang Jinhe. Quantitative Relationship Analysis between China`s Economic Growth and the Electric Development[J].The Journal of Quantitative \& Technical Economics,2002,(10)

[6] Shu Fan. The Price Elasticity of Electricity Demand in South Australia [J]. Energy Policy, 2011, 39(6):3709-3719

[7] Si Zengchuo. The Relativity among Industrilization Process and Evolution Process of Elasticity Ratio of Electricity Consumption in China[J].Industrial Economic Review,2011,(1)

[8] Qiu Weijie. The Grey Control System and its Research on Elastic Coemeient of Electrieity Consumption in China [J]. Economic Survey,2005,(5)

[9] Sajal Ghosh. Electricity Consumption and Economic Growth in India [J]. Energy Policy, 2002, 30(2):125-129

[10]Lin Boqiang. Electricity Consumption and Economic Growth in China: a Study based on Production Function [J]. Management World,2003,(11)

[11] Muhammad Shahbaz. The Dynamics of Electricity Consumption and Economic Growth: A Revisit Study of Their Causality in Pakistan [J]. Energy, 2012, 39(1): 146-153

[12] Li Ke. Relationship between Electricity Consumption and Economic Growth of China based on Threshold Regression Model [J]. System Engineering Theory and Practice,2012,32(8)

[13] Paresh Kumar Narayan. Multivariate granger causality between electricity consumption, exports and GDP: Evidence from a panel of Middle Eastern countries [J]. Energy Policy, 2009, 37(1): 229 $-236$

[14] James E. Payne. A Survey of the Electricity Consumption-growth Literature [J]. Applied Energy, 2010,87(3):723-731

[15] Niu Dongxiao. An Empirical Study on the Relationship between Electricity Consumption and Economic Growth in China [J]. Statistics and Decision, 2013, (2)

[16] Henryk Gurgul. The Electricity Consumption Versus Economic Growth of the Polish Economy [J]. Energy Economics,2012,34(2):500-510

[17] Alice Shiu. Electricity Consumption and Economic Growth in China [J].Energy Policy,2004, 32(1):47-54

[18] Dong Zhi. Analysis of Variety Status of Electricity Consumption Elasticity Coefficient in Henan [J]. Power System Protection and Control,2010,38(5)

[19]Zhou Jinghong. Co-integration Analysis on Electricity Consumption and Economy Increase in Jilin Province [J]. Jilin Electric Power,2012,40(1) 